\title{
Automotive Product Engineering Design Project for Fourth Year Undergraduate Engineering Students
}

\author{
Peter R. Frise, William J. Altenhof \\ University of Windsor
}

\begin{abstract}
This paper outlines the rationale, development, and implementation of an automotive product engineering design project for fourth year mechanical engineering undergraduate students at the University of Windsor. The purpose of the project was to give undergraduate students an opportunity to work together as a group, to develop a simple three part automotive component and experience the steps required to develop a typical automotive product engineering project.

The component was a small module which was required to fit into an air vent in an existing vehicle bumper. The three parts of the component were required to be easily assembled to produce the final product and the fit of the assembly into the bumper was evaluated. In addition, the assembled components were tested for their ability to withstand an impact load. Dimensional design constraints on two of the three parts were selected by the authors and presented to the students at an early stage of the design process. The component which each group designed, developed, and manufactured was evaluated based upon the weight, dimensional deviation from the given design constraints, ease and efficiency of assembly, impact resistance, and aesthetics. In addition, each group was required to submit complete CAD drawings illustrating the orthogonal views of each part in their component and an isometric assembly drawing.
\end{abstract}

This paper will present the methodology, development, and implementation of the automotive product design project. The evaluation procedure of the project will be addressed and several recommendations for improvement on the design project will be presented.

\section{Introduction and Rationale}

Engineers employed in industry are required to work with other companies, as well as with designers and engineers from their own organization. This is especially prevalent in the modern automotive industry where vehicles are the product of many company's work as different vehicle components and systems are sourced from different companies. Difficulties in designing, developing, and manufacturing components often arise when several individuals work together on the same project.

Aside from the commonly experienced personnel issues, the whole process of designing a product to meet a specification, parts of which may be unclear, contradictory or the subject of unavailable information along with reconciling manufacturing styles and capabilities of different people and organizations is key to becoming a successful and technically mature design engineer. 
In an effort to illustrate the various problems associated with the design, production, assembly and testing of any mechanical component (in other words, a complete cycle of a typical industry product development project) the final year Automotive Engineering students at the University of Windsor in the "Elements of Mechanical Design" course, were assigned a design project that required them to design and manufacture a three part automobile component as a team.

This project involved the design and fabrication of a component which was to be integrated into an air cooling inlet vent in the front bumper of a 1998 Dodge Ram 1500 pickup truck. The scenario presented to the class was that they were competing for a contract to design a new type of electric fog lamp module for the Dodge Ram and it had to integrate with the existing bumper sheet metal. The assignment was to produce a simple physical mock-up of the module in pink styrofoam insulation material.

The product engineering development process we are emulating in this project is shown in the flowchart in Figure 1 below.

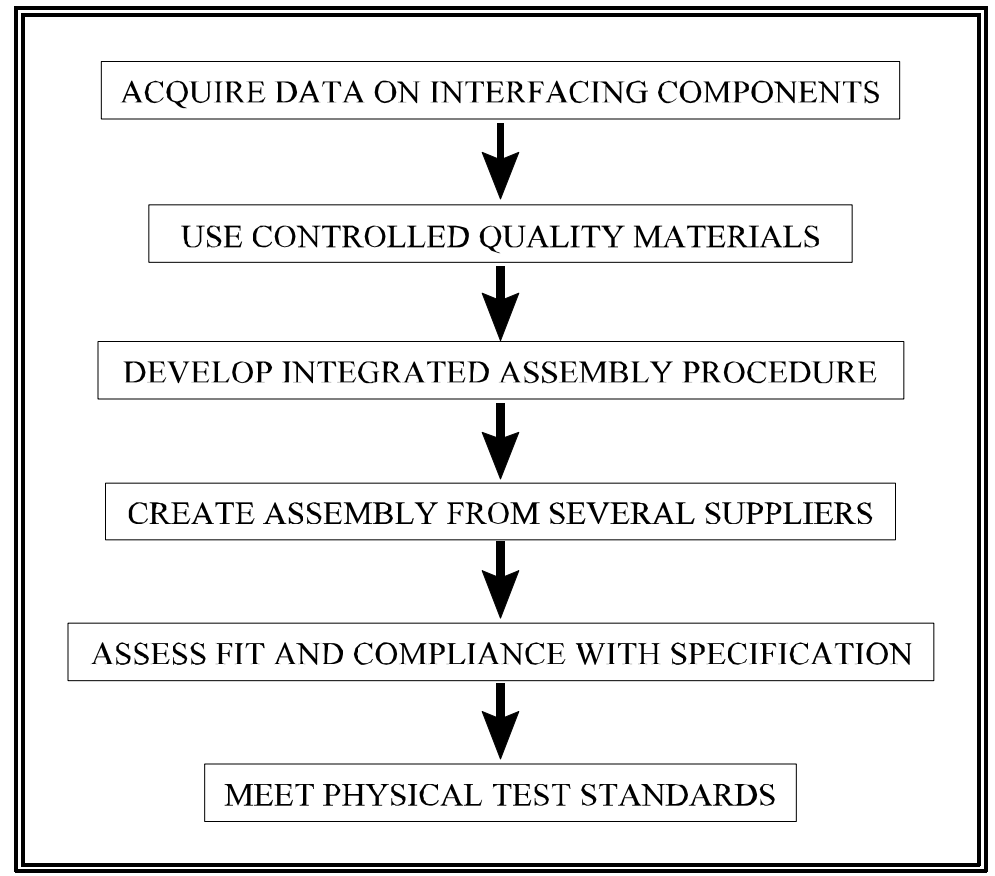

Figure 1 - Product development flowchart.

\section{Team Interaction in Product Development}

Regardless of the magnitude of any project which an engineer undertakes from his/her company, collaboration with additional engineers, designers, and other personnel within the corporation and with other corporations will occur. The class was divided into teams of three students, each member being responsible for the design and manufacture of one of the three parts of the assembly. 
The rationale behind dividing the class into different groups and further dividing responsibilities within each group was to emulate the collaboration between engineers and companies that occurs daily in industry. It was our intention to require each student to work individually on his/her component and additionally required him/her to cooperatively work with other students within each group so that the assembled component would be a successful product.

\section{Design Constraints}

To further model a typical industrial project, design constraints (linear dimensions) were imposed on two of the three parts as well as on the overall length of the assembled component. In addition, the materials used in the component were specified (in fact they were supplied to the class). The three parts of the assembly were to be made of pick styrofoam insulation material and this was to be the only material that was visible once the three parts are assembled into a finished component. This material is an ideal choice for student projects because it is widely available at low cost and it can be carved and shaped without complex or expensive machine tools. The constraint also forced the students to develop a strong part-to-part interface which is not visible in the assembled component.

The students were aware that deviation of the actual dimensions from the design specifications would be considered in the evaluation of their component. By imposing design constraints on only two of the three components along with the overall assembly dimensions, the students were required to coordinate their work to produce an assembly which met the product specification. On the other hand, the openness of certain aspects of the specification gave the students flexibility to design their own parts and it ensured that each group's work would have significantly different geometries.

To ensure that the students within each group did work together, the ease of assembly as well as the dimensional compliance of the assembly was evaluated in the testing and grading phase of the project just as they would be in a real industry product evaluation process..

Automotive manufacturers require that their products be lightweight and aesthetically pleasing. In addition, structures associated with vehicle bumpers must be capable of withstanding an impact from projectiles. All of these factors were considered in the evaluation of each group's design. Each component was weighed, evaluated for aesthetic appeal and tested for resistance to impact from a small projectile dropped from a measured height.

All of these elements are very significant in any automotive component. It was felt necessary to include these factors into the fourth year product engineering design project which would illustrate to students the actual requirements associated with automotive product development.

\section{Development \& Implementation}

This design project was given to the fourth year mechanical engineering students, registered in "Elements of Mechanical Design", at the University of Windsor as a compulsory part of the course. Early in the semester, the class was given a presentation on the requirements, the 
proposed constraints, and the evaluation of the project. Each student was provided with a handout which illustrated the requirements and constraints which must fulfilled by their group's component.

Figures 1 and 2 below, were provided to the students to respectively illustrate a typical three part component which must fit into the bumper and the typical constraints imposed on two of the three parts. In addition, the students were informed that their components were to be evaluated based upon the component's weight/mass, deviation from design constraints, ease of assembly, impact resistance, an aesthetics. Furthermore, a subjective evaluation mark was also to be assigned for

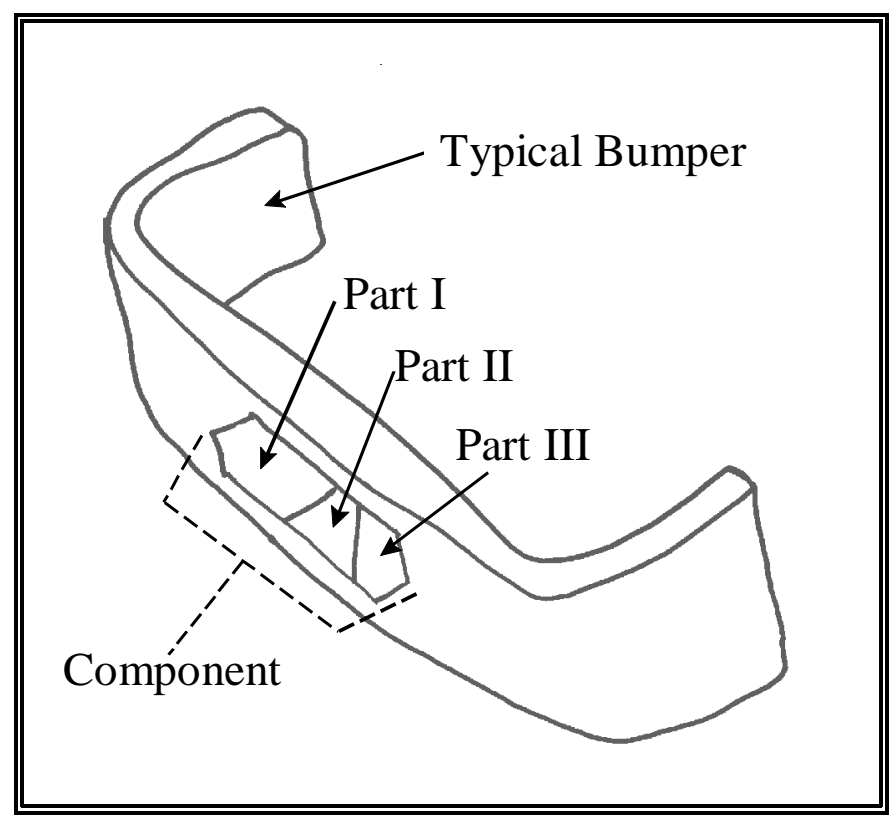

Figure 2 - Illustration of the component of the bumper to be developed. Each component consists of three parts.

other aspects of their design, such as ingenuity, and grading of the Computer Aided Drawings (CAD) was also to be conducted.

A mathematical expression was developed to assign an overall "Grade of Component" (GOC) for each groups project. This equation (Equation 1) considered the mass of the component, the dimensional deviation from the design requirements, the ease of assembly (EOA) of the three parts to form the single component, the impact resistance of the

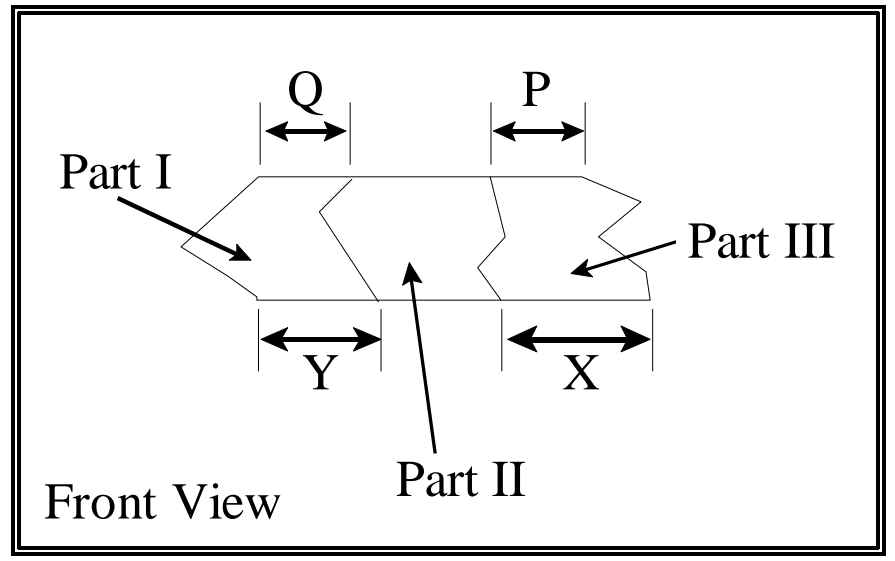

Figure 3 - Each part of the entire component with specified dimensions. 
component, the aesthetics of the component, and an additional "subjective evaluation" term.

GOC $\quad \frac{\text { Mass }}{\text { grams }} \% \frac{(\text { ActualDimension\&DesignConstraint })}{m m} \%$ E.O.A. \%mpact \% Aesthetics \%S.E.

(Equation 1)

Evaluation of the last four terms in Equation 1 (ease of assembly, impact performance, aesthetics, and subjective evaluation) were based upon a maximum of ten (10) possible marks.

\section{Data Gathering}

One of the key factors often neglected in capstone design projects assigned to students is the fact that most designs must integrate with an existing system or piece of hardware - few devices or systems are designed from the outset as stand-alone items. The process of integrating one's design with the work of others is sometimes a difficult task and one which many young engineers find difficult and so we felt that it was important that the product engineering design project place this additional requirement on the students.

In addition the Elements of Mechanical Design course included a significant amount of laboratory material on metrology including the use of precision measurement hand tools as well as coordinate measuring machine (CMM). This material is felt to be important to give the students an appreciation of tolerancing and impart an understanding of how parts with complex geometries fit together. The other key point is that drawings and CAD data for existing components are often not available and so it is essential that product engineers be able to make accurate physical measurements using metrology instruments.

As noted above, the lighting module which the students were mocking-up in the present project was to become a component of the front bumper of a Dodge Ram 1500 pick-up truck and so it was essential that the student have access to such a bumper.

The University of Windsor jointly owns and operates a modern $15,000 \mathrm{~m}^{2}(160,000$ sq. ft.) Automotive Research and Development Centre (ARDC) with DaimlerChrysler Canada Inc.

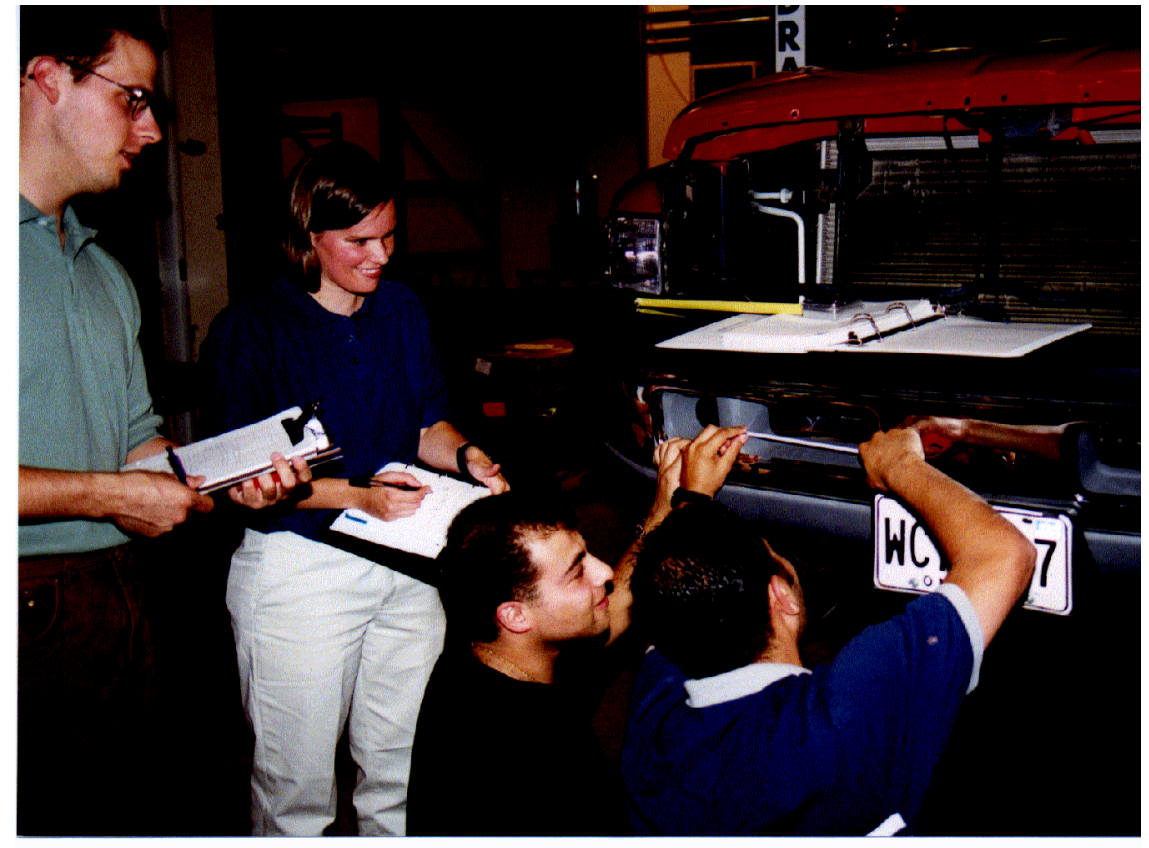

Figure 4 - Students measuring geometry of a truck bumper. 
and the class was taken on a field trip to ARDC to facilitate the gathering of geometric data on the Dodge truck bumper. The students were given a set of metrology instruments and access to the truck which was sitting on a hoist at a convenient working height. This session took about 1.5 hours for everyone to gather all the data which they felt they would need to produce their lighting module product. Figure 4 depicts the students measuring the air vent geometry from the Dodge truck bumper.

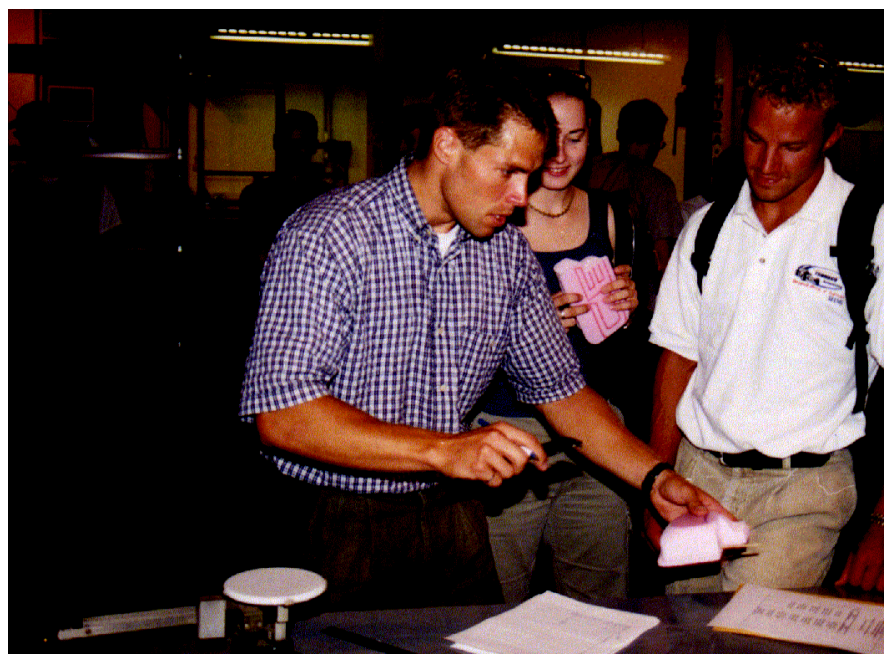

Figure 5 - Evaluation of the component.

\section{Testing}

The class was once again taken to ARDC for the product test and evaluation session. The evaluation consisted of (in the following order):

1. Dimensional measurement of the parts and assembled components to evaluate the compliance of the product with the dimensional constraints in the specification. Figure 5 shows the evaluation process of one group's component.

2. Weighing of the assembled component.

3. A subjective evaluation of the ease and efficiency of assembly of the three parts into an assembled product.

4. An evaluation of the aesthetics and the fit of the assembled component onto the truck bumper (Figure 6).

5. A subjective evaluation of the groups' work based upon ingenuity and design.

6. A mechanical impact test in which objects were dropped onto the assembled component from a measured height (Figure 7).

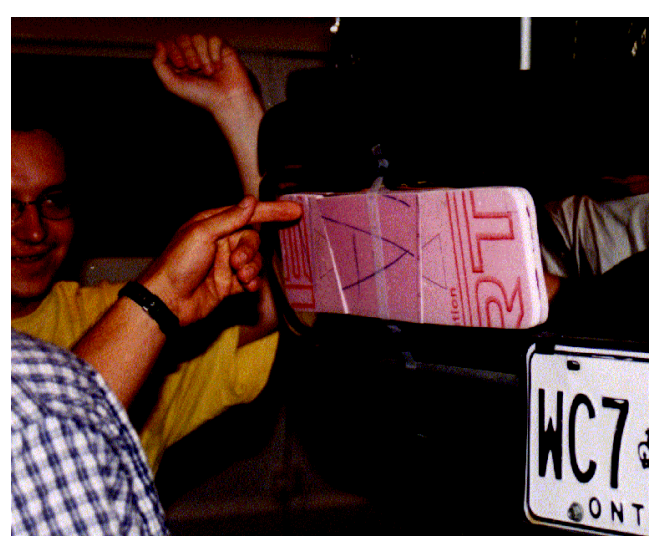

Figure 6 - Evaluation of the fit.

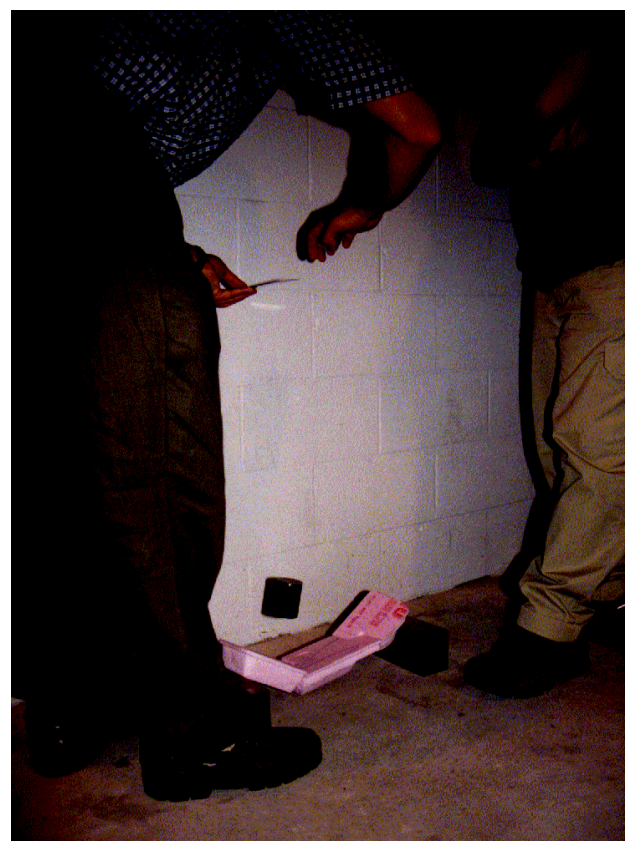

Figure 7 - Impact testing. 
Equation 1 was used to determine a mark (GOC) for each groups' component based upon the six evaluation steps. A final overall project mark, for each group, was derived from the GOC and evaluation of the CAD drawings.

\section{Conclusions and Recommendations for Future Offerings}

This simple design project worked well to show the students how a typical automotive product engineering product development project is conducted. It demonstrated the basic phases and process which all successful product development project must go through including data gathering on the existing interface components, integration of several suppliers (in this case team members) design and manufacturing capabilities, customer evaluation including a significant element of esthetic and subjective evaluation, and finally a physical testing phase in which the test requirements were somewhat vaguely defined in advance.

We are generally satisfied with the outcomes of this project but we did note some aspects which could be improved upon. We will increase the complexity of the component in future and it may be desirable to have the students draw their parts first and then pass their drawings onto a classmate without signing the drawings. This will bring out the importance of providing good complete and correct drawings to them as they attempt to manufacture parts from drawing which they have not done themselves.

\section{Acknowledgments}

The assistance and financial support of the Natural Sciences and Engineering Research Council of Canada (NSERC) and DaimlerChrysler Canada Inc. in conducting this project is gratefully acknowledged.

\section{PETER FRISE}

Peter Frise holds Bachelor's and Master's degrees in mechanical engineering from Queen's University in Kingston and a Ph.D., from Carleton University in Ottawa. He began his career in Nigeria as a Wireline Logging Engineer for Schlumberger Wireline Services and later worked in R\&D for Husky Injection Molding Systems in Bolton, Ontario. In 1988 he joined the Faculty at Carleton University in Ottawa and in 1993 he received the Ralph R. Teetor Engineering Education Award from the SAE. He serves on the Governing Council of the Association of Professional Engineers of Ontario as well as on the Complaints Committee of the Association and he is active in consulting. Peter is presently Professor and DaimlerChrysler Canada/NSERC Industrial Research Chair in Mechanical Design at the University of Windsor where he is developing Canada's first program in Automotive Engineering.

\section{WILLIAM ALTENHOF}

William Altenhof holds Bachelor's, Master's, and a Ph.D. from the University of Windsor. During the completion of his Ph.D. work, he was hired as a Research Engineer with K.S. Centoco, where the focus of his work is on steering wheel research and development. In the summer of 1999 he joined the Faculty of Mechanical, Automotive, and Materials Engineering at the University of Windsor as an Assistant Professor in the field of Solid Mechanics. 